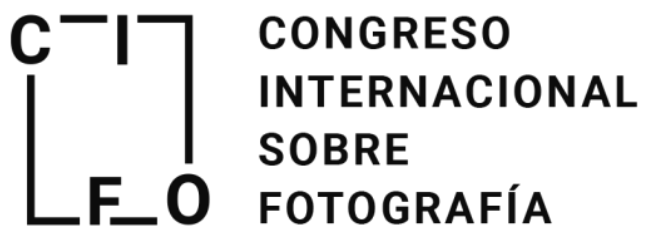

Congreso Internacional sobre Fotografia

UPV, 5 y 6 octubre 2017

Doi: http://dx.doi.org/10.4995/CIFo17.2017.6762

ISBN: 978-84-9048-604-7

\section{Vistas de Madrid. La ciudad corporativa}

\section{Ricardo Espinosa Ruiz}

Universidad Complutense de Madrid, ricaresp@ucm.es

\begin{abstract}
In the last few years, the most important corporations have tended to move their headquarters from Madrid downtown to locations outside the city. During the second half of the 20th century cities experienced an industrial emptying that became basically new residential space. Now, this new corporate emptying generates a new city model, based in tourism and leisure spaces. Some of the neoliberal city characteristics are confirmed: specialization of the space, with private management instead of public, and the creation of a brand image for the cities that allows them to compete with the other cities for the resources, inside a free market frame. This photographical series is based in the practice-based research, and focuses in the construction of the urban landscape in Madrid during the last decades. Reinterpretates the representation of the "veduta", a style that came up around the phenomenon of the XVIII century Venetian tourism that shows a secular vision of the town.
\end{abstract}

Keywords: Photography, urban landscape, veduta, Madrid, practice-based research

\section{Resumen}

Las grandes corporaciones han tendido en los últimos años a desplazar sus sedes desde los distritos del centro de Madrid hacia posiciones periféricas. Si en la segunda mitad del siglo XX la ciudad asistió a un vaciado industrial, que dio pie básicamente a nuevos espacios residenciales, este nuevo vaciado corporativo genera un nuevo modelo de ciudad centrado en los usos turísticos y el ocio. Se confirman algunos de los estándares de la ciudad neoliberal: especialización del espacio y cesión de su gobierno al capital privado en detrimento de la gestión pública, y creación en torno a la ciudad de una imagen de marca, que permite competir con otras ciudades por la atracción de capital dentro de una lógica de libre mercado. La serie fotográfica que compone este trabajo, inscrita en el marco de la investigación basada en la práctica, se centra en la construcción del paisaje urbano en Madrid en las últimas décadas. Replantea la representación de la "veduta", género surgido en torno al fenómeno del turismo véneto del siglo XVIII, que muestra una visión laica de la ciudad.

Palabras clave: Fotografia, paisaje urbano, veduta, Madrid, investigación basada en la práctica 
Vistas de Madrid. La ciudad corporativa.

\section{Introducción}

Dentro de la representación tradicional de la ciudad, vistas, caprichos y ruinas nos muestran tres puntos de vista que nos ayudan a formar una idea de la misma. Las ruinas hablan de una trayectoria. Son el pasado, pero sobre todo el lugar de reflexión. Los caprichos son una ficción. Su nombre nos indica que estamos ante una escena que aunque muestra parte de realidad también tiene una fuerte carga interpretativa. Por último, las vistas nos introducen en la representación más fiel de ciudad, acotando determinados fragmentos relevantes de su hacer cotidiano. El objetivo de este trabajo fotográfico es el de mostrar el paisaje urbano construido en las últimas décadas en la región metropolitana de Madrid a través de un serie de vistas, que aunque efectivamente muestran fragmentos, junto con este trabajo de investigación permiten conformar una lectura de la misma que nos ayuda entender su evolución. Este trabajo se inscribe dentro de la investigación basada en la práctica, definida por Borgdorff (2010) de la siguiente manera:

La práctica artística puede ser calificada como investigación si su propósito es aumentar nuestro conocimiento y comprensión, llevando a cabo una investigación original en y a través de objetos artísticos y procesos creativos. La investigación de arte comienza haciendo preguntas que son pertinentes en el contexto investigador y en el mundo del arte. Los investigadores emplean métodos experimentales y hermenéuticos que muestran y articulan el conocimiento tácito que está ubicado y encarnado en trabajos artísticos y procesos artísticos específicos. Los procesos y resultados de la investigación están documentados y difundidos de manera apropiada dentro de la comunidad investigadora y entre un público más amplio.

\section{El vaciado corporativo}

El Ibex 35 está formado por las 35 empresas españolas con mayor liquidez, es decir, aquellas cuyas acciones generan mayor movimiento de compra y venta en las sedes de la Bolsas española en Madrid, Barcelona, Bilbao y Valencia. Las empresas que lo componen van cambiando en el tiempo, y van formando parte de él o lo van abandonando en revisiones que se realizan un par de veces al año. De hecho, desde su creación en el año 1992, han sido un centenar de empresas las que han sido incluidas en algún momento dentro de dicho índice.

Hacer un seguimiento de donde se han ubicado las sedes de las empresas que lo conforman nos proporciona una muestra de cómo se posicionan geográficamente dentro de la ciudad las corporaciones nacionales, lo cual es un hecho importante a la hora de configurar el paisaje urbano de Madrid. En los mapas se reflejan las sedes de las empresas que lo componían en el momento de su creación en enero de 1992 (ver figura 1) y las que formaban parte de él tras la revisión de diciembre de 2016 (ver figura 2). Como podemos observar estas empresas tienden a desplazarse a la zona periférica de la ciudad, especialmente al norte y al noreste, en detrimento de la zona central incluida dentro de la circunvalación de la M-30. El 2 de enero de 1992, fecha en la que comienza el Ibex 35, de los treinta y cinco valores, veintitrés tienen su sede en Madrid. De estos, sólo una empresa tiene su sede fuera del radio de la M-30. En comparación, el 19 de diciembre de 2016, de los veintidós valores, nueve se sitúan dentro del cinturón de la M-30, mientras que en la parte exterior encontramos trece de ellas. 


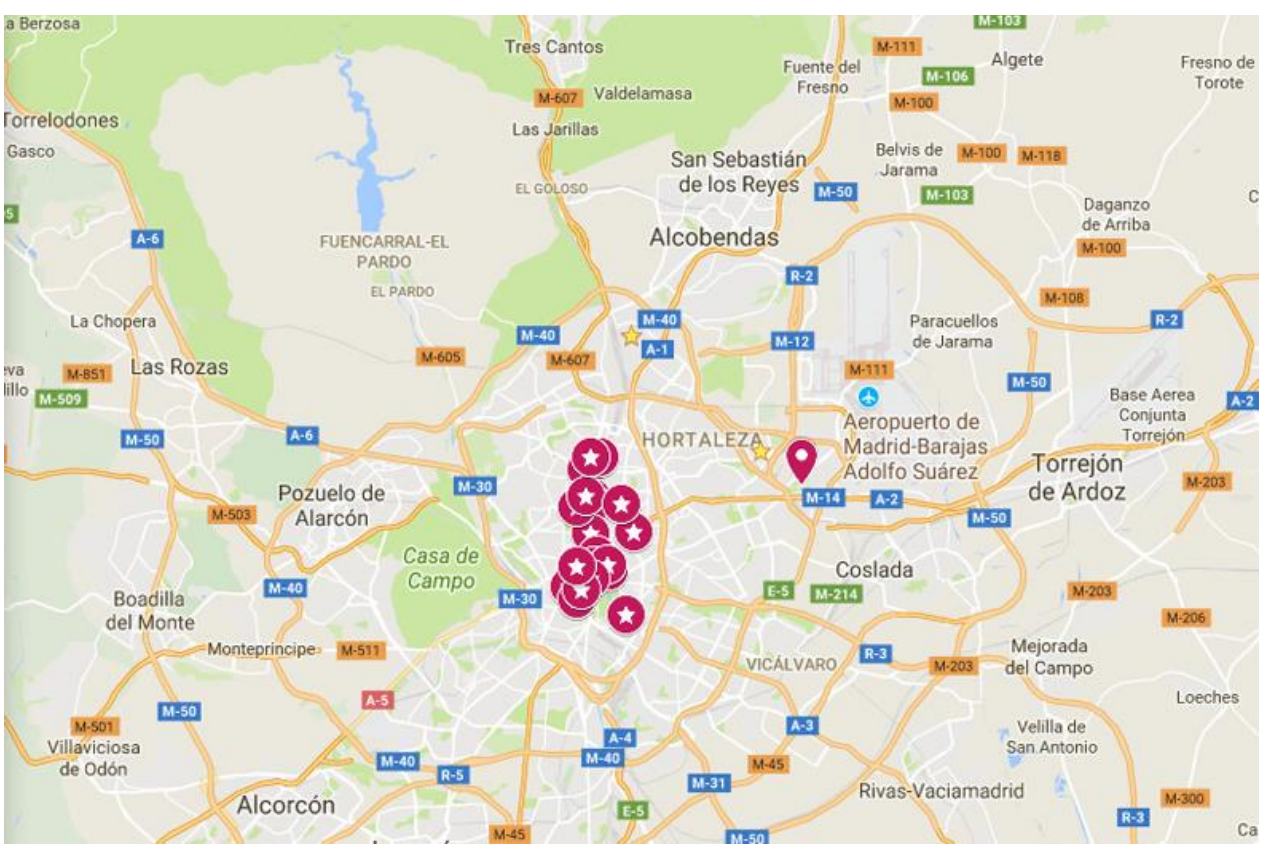

Fig. 1 Localización de las empresas del lbex35 el 2 de enero de 1992.

Fuente: Anuario de sociedades, consejeros y directivos (1991). Madrid: Dicodi Anuario de sociedades, consejeros y directivos (1993). Madrid: Dicodi

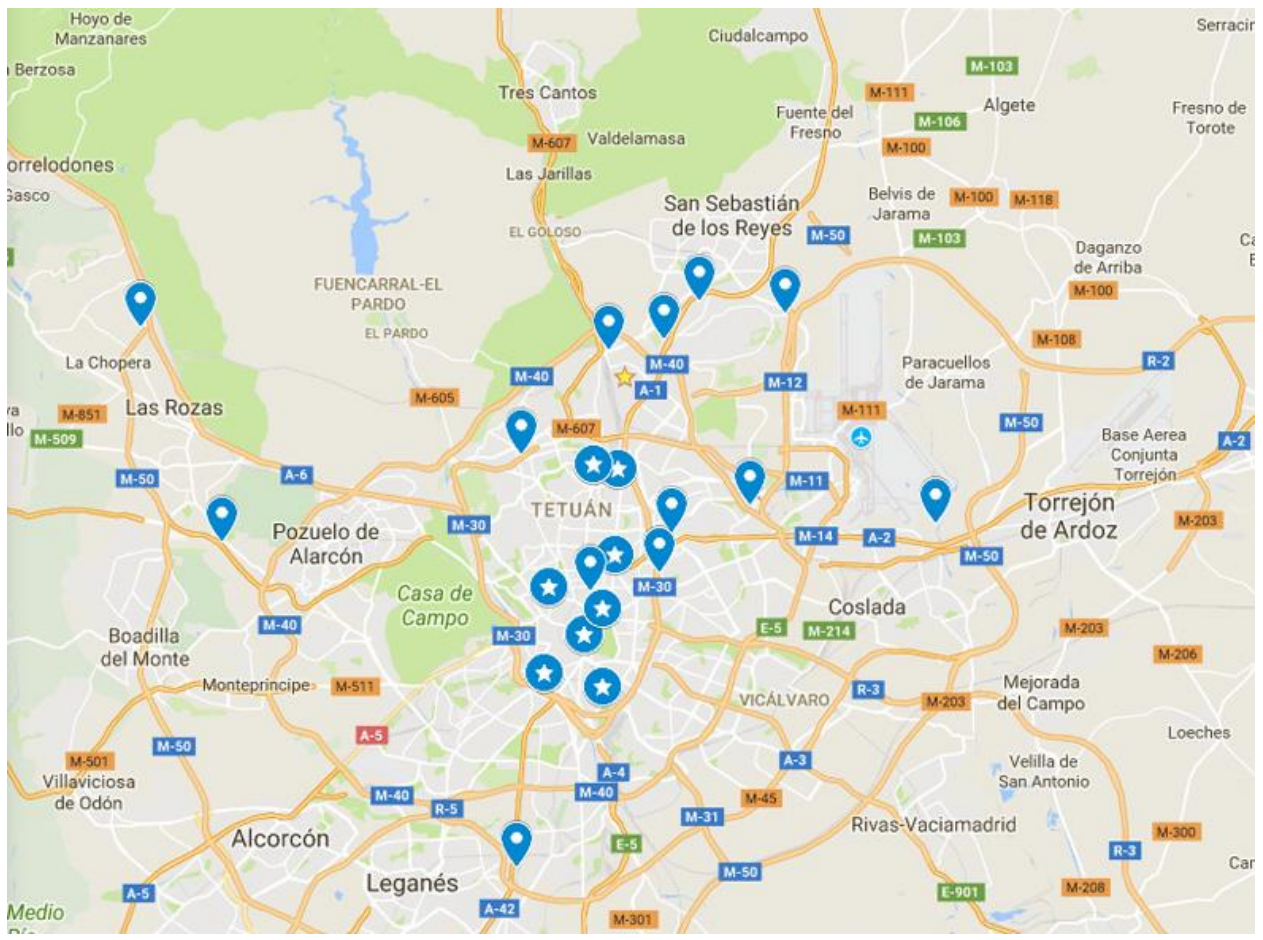

Fig. 2 Localización de las empresas del Ibex35 el 19 de diciembre de 2016.

Fuente: Base de Datos de las principales empresas españolas (2012/2013). Madrid: Dicodi

Además, es importante resaltar que la nueva ocupación del territorio que realizan para sus sedes estas empresas no es similar a la que podemos encontrar en el centro. Si las antiguas sedes del centro estaban integradas en la ciudad, estas nuevas ciudades corporativas son espacios en los cuales la administración pública ha sido sustituida por la inversión privada (Loukaitou-Sideris y Banerjeeson, 1998), en las que las actividades que se 
Vistas de Madrid. La ciudad corporativa.

realizan en la ciudad tradicional, tanto de ocio como servicios, se incorporan al recinto de la empresas para uso de los trabajadores, siendo en algunos casos áreas de acceso restringido. Vemos como esta tendencia de las grandes empresas va más allá de la construcción de un edificio emblemático que sea representativo, y se propone como una alternativa al espacio común de gestión pública, lo que supone un cambio en la relación con la ciudad que le rodea y por lo tanto de su paisaje urbano. Esta idea de ir creando espacios corporativos ubicados en la zona periférica de la ciudad se corresponde principalmente con una lógica de optimización económica. La idea básica es común en todos los casos, y se puede resumir de la manera siguiente: intentar agrupar en una única localización los espacios de trabajo de una compañía que anteriormente estaban dispersos por la ciudad, para conseguir una mejor eficiencia económica. La Ciudad Financiera del Banco de Santander, situada en Boadilla del Monte, ha sido una de ellas. Alfonso Millanes, arquitecto que trabaja para el Santander desde 1978 lo explica de la siguiente forma:

\begin{abstract}
El Santander creció tanto que, llegado un momento, decidió centralizar y optimizar su operativa creando la Ciudad Financiera. Además de lograr sus objetivos, resultó ser una operación inmobiliaria evidente, ya que le permitió poner a la venta grandes edificios en las mejores zonas de Madrid. Remató la operación con la idea de vender el inmovilizado y quedarse con un alquiler de 50 años y posibilidad de recompra... Una gran operación, sin duda: eliminas departamentos duplicados; centralizas los centros de decisión; dejas de pagar a Hacienda por el inmovilizado; desgravas por los alquileres... (Volumen, 2013)
\end{abstract}

En el espacio que se dedica en la página web del Banco Santander para dar a conocer la sede corporativa, viene descrita de una manera más amable para sus trabajadores: se titula 'Pensada para los empleados' y, en él encontramos tres fotografías: la primera muestra a dos médicos con bata blanca y sus correspondientes estetoscopios comentando un posible informe en una sala de consulta completamente equipada. La segunda es una vista aérea donde se muestran las instalaciones deportivas, un gran lago y zona ajardinada. En la tercera podemos ver una actividad que se realiza en el patio de una escuela infantil. A continuación, un texto donde se comentan las comodidades para los empleados:

\footnotetext{
La Ciudad Grupo Santander ofrece grandes ventajas a los trabajadores (...) cuenta con un Centro de Formación con capacidad para 600 alumnos (...) También existe un centro de educación infantil (...) En un recinto de estas características no podían faltar instalaciones deportivas: el centro deportivo dispone de un gimnasio dotado de todas las últimas innovaciones tecnológicas en fitness o clases deportivas colectivas, piscina cubierta, varias decenas de pistas de tenis y pádel, campos de fútbol 7 y fútbol 11, baloncesto y voleibol, volley-playa, un moderno circuito de jogging, un campo de golf (...) todo ello está comunicado por líneas internas de autobús. (Banco de Santander, sin fecha).
}

Vemos en ella una emulación de la ciudad tradicional con sus servicios dedicados a salud y educación, amplias zonas de ocio donde también tienen cabida una importante sala de exposiciones y locales de restauración, e incluso su propio transporte público para conectar los diferentes espacios. Todo ello, lógicamente, de gestión privada y con un acceso restringido, es decir, una ciudad privatizada. Esta no es una idea exclusiva de las empresas privadas, también la Comunidad de Madrid intentó construir una Ciudad de la Justicia ideada bajo la misma lógica, venta de las diferentes sedes distribuidas por la ciudad y concentración en un único punto, también en la zona noreste de Madrid. El discurso de la ciudad compacta versus la ciudad dispersa no es ajeno a estos proyectos.

Desde los años cincuenta hasta mediados de la década de los ochenta del siglo XX se produce en Madrid un desplazamiento de las industrias radicadas en la zona central de Madrid hacia la periferia, dando pie a un 
vaciado industrial que permite liberar suelo y que genera nuevos usos de las parcelas (Pardo, 2004). En el caso particular de Madrid, el 80,2\% del espacio de estas parcelas será reconvertido para uso residencial. Como resultado, surge un nuevo paisaje urbano condicionado por el nuevo uso del territorio. Lo que sugieren estos mapas es que estamos asistiendo a un nuevo vaciado, en este caso corporativo, en el que las grandes empresas reubican sus sedes en zonas alejadas del centro de la ciudad, y por lo tanto, generando un nuevo paisaje, tanto en las nuevas zonas como en el centro. Por ello, no sólo es interesante observar el desplazamiento de las sedes de estas empresas hacia los bordes de la ciudad para la creación de sus espacios privados, sino también entender qué sucede con los vacíos que dejan en el centro, especialmente, tras la crisis de 2008.

Según Harvey (2009), cada crisis del capitalismo requiere moverse hacia un "plano superior", y para ello indica cuatro elementos utilizados de manera superpuesta que sirven para conseguir ese ascenso de plano. El primero es la "penetración del capital en nuevas esferas de actividad organizando las formas de actividad preexistentes conforme a los métodos capitalistas" (Ibid.). Por ejemplo, resulta evidente la explotación bajo lógica del capital que se hace de la cultura en museos, centros culturales y exposiciones, a las que se exige un rédito económico. Parte de este vaciado corporativo da lugar a espacios dedicados a este tipo de consumo cultural. El segundo es el "crear nuevos deseos y necesidades sociales, desarrollando líneas de producto completamente nuevas (los automóviles y los aparatos electrónicos son excelentes ejemplos del siglo XX) y organizar el consumo de manera que se vuelva racional respecto al proceso de acumulación" (Ibid.). La introducción del shopping en la cultura del ocio genera y habilita nuevos espacios que ya no están situados tan solo en el centro comercial de la periferia de la ciudad, sino en los huecos que van dejando estas compañías. En tercer lugar "facilita y fomenta la expansión de la población a un ritmo consecuente con la acumulación a largo plazo" (Ibid.). Para ello, será necesario conseguir consolidar la ciudad dentro de un circuito turístico que permita que la aportación de población, en este caso fluctuante, sea suficiente como para poder mantener activos los espacios creados, ya que únicamente la población residente no sería suficiente para lograrlo. Por último, será necesario "expandirse geográficamente hacia nuevas regiones, aumentar el comercio exterior, exportar capital y en general expandirse hasta crear lo que Marx denomina el mercado mundial" (Ibid.). Podemos considerar al propio turista como una mercancía valorizable, y su tiempo de rotación será especialmente importante. Para ello será fundamental la mejora de los sistemas de transporte, y en este caso su bajo precio que permita la aceleración de ese sistema de rotación, y que fomente el uso del centro de la ciudad para un uso turístico. Aplicando este modelo, vemos como el desplazamiento del centro urbano hacia las ciudades corporativas ubicadas en la periferia, deja sitio al "lugar especializado" (Muñoz, 2008) que se caracteriza por ser un espacio en el que el ocio y el consumo cubren las necesidades de un turismo global, y sirven como modelo de nuevo crecimiento económico

\section{Ciudad y datos}

En los datos relativos al censo de locales y sus actividades, que forman parte de los datos abiertos que ofrece el Ayuntamiento de Madrid, podemos encontrar información relevante. Las cifras que se pueden consultar son mensuales, y de ellos, vamos a seleccionar únicamente los locales que en cada momento figuran como abiertos, excluyendo por lo tanto los que estén cerrados, en obras, o que se usen como vivienda. Estos a su vez se agrupan en diferentes categorías, siendo las más frecuentes 'Comercio y talleres mecánicos' (42,7\%), 'Hostelería' $(16,6 \%)$, 'Educación’ (3,9\%) y ‘Sanidad' (3,6\%) (véase la figura 3). 


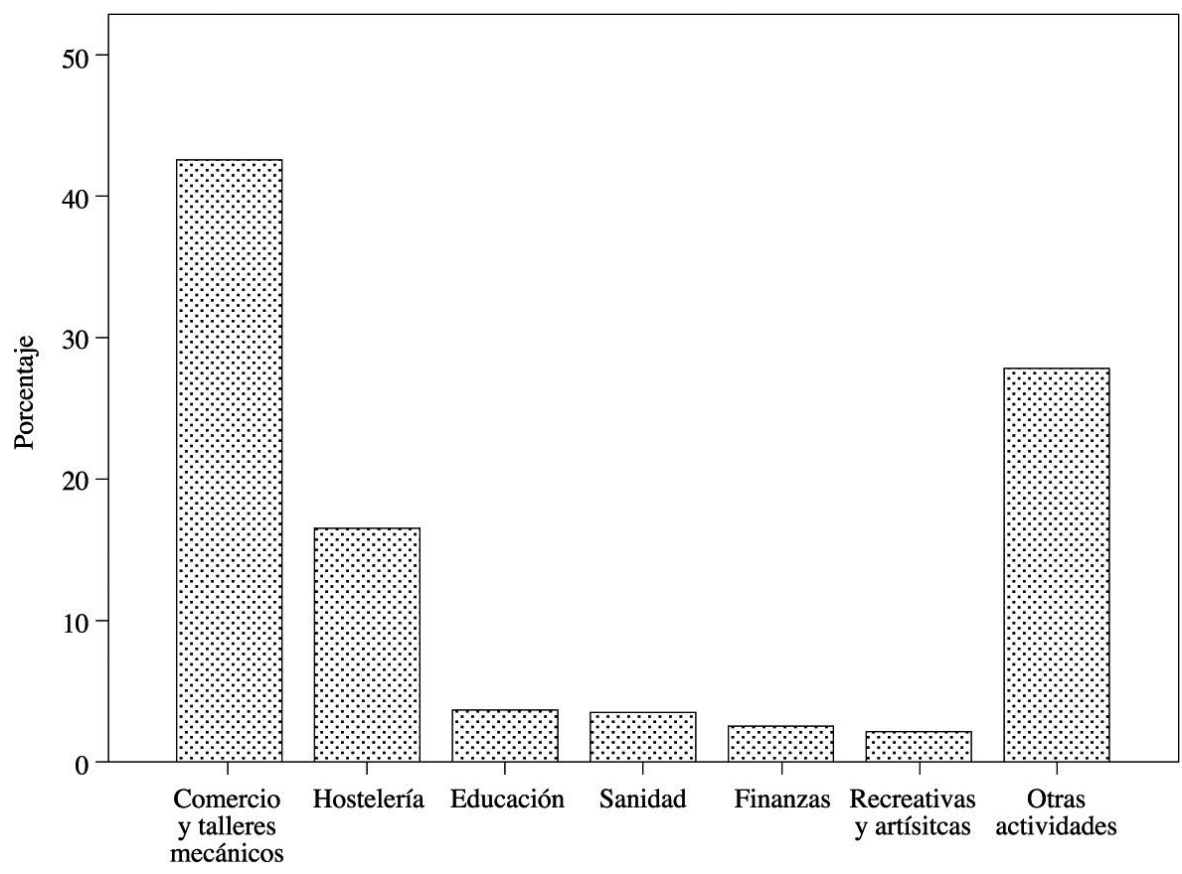

Fig. 3 Distribución de las actividades de los locales en Madrid.

Fuente: Ayuntamiento de Madrid

Ocio y consumo son rasgos que definen a la nueva ciudad orientada hacia el turismo. Será necesario por lo tanto ampliar la oferta de los negocios dedicados a satisfacer las nuevas necesidades que se generan en torno al nuevo modelo de espacio dedicado al recreo. La búsqueda de nuevas experiencias hace de la gastronomía un sector atractivo. El hecho de que se trate de una experiencia local también es importante, ya que dentro del mundo global, el turista va a buscar siempre esa pequeña diferencia que le permita sentirse parte integrada en la comunidad que visita. Este sector, junto con el del hospedaje serán de uso necesario para el visitante y son los que encontramos bajo la categoría de 'Hostelería'.

Para el análisis que nos interesa, vamos a dividir la ciudad en dos áreas. Una es la zona central, delimitada por el primer anillo de circunvalación de la ciudad que incluye el área interior de la calle 30 (M-30), conocida también como almendra central, y que engloba siete distritos: Tetuán, Chamartín, Chamberí, Salamanca, Retiro, Centro y Arganzuela. La otra es aquella que queda en la zona exterior y que corresponde a los catorce distritos restantes (ver figura 4). 
Ricardo Espinosa Ruiz

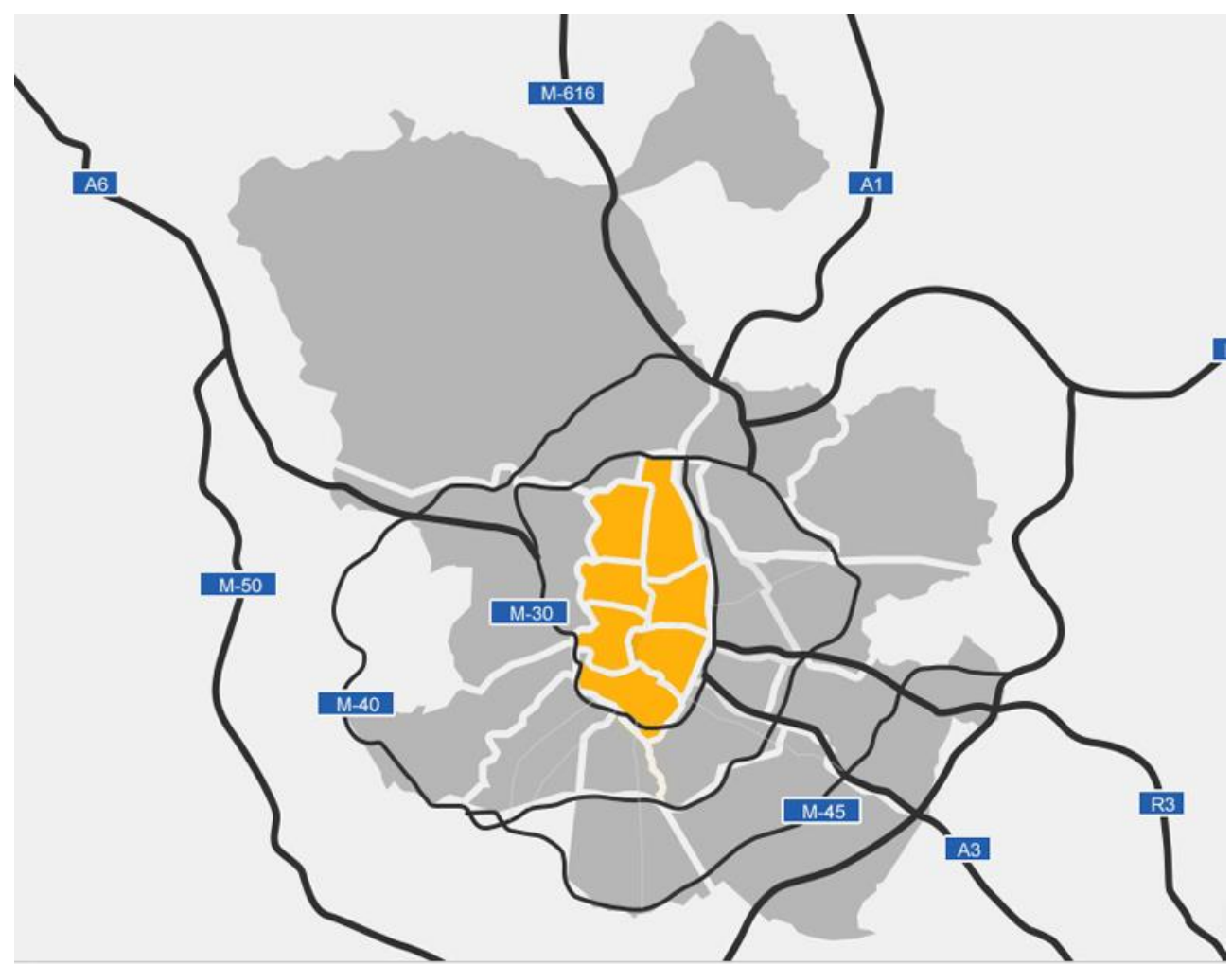

Fig. 4 Mapa de los 21 distritos de Madrid. En naranja los incluidos dentro de la circunvalación de la M-30. Fuente: Ayuntamiento de Madrid

El área de la zona exterior es significativamente más grande que la de la zona interior, pero a pesar de ello, la distribución de los locales no es tan grande como cabría esperar (del $57 \%$ frente al $43 \%$, véase la figura 5 ).

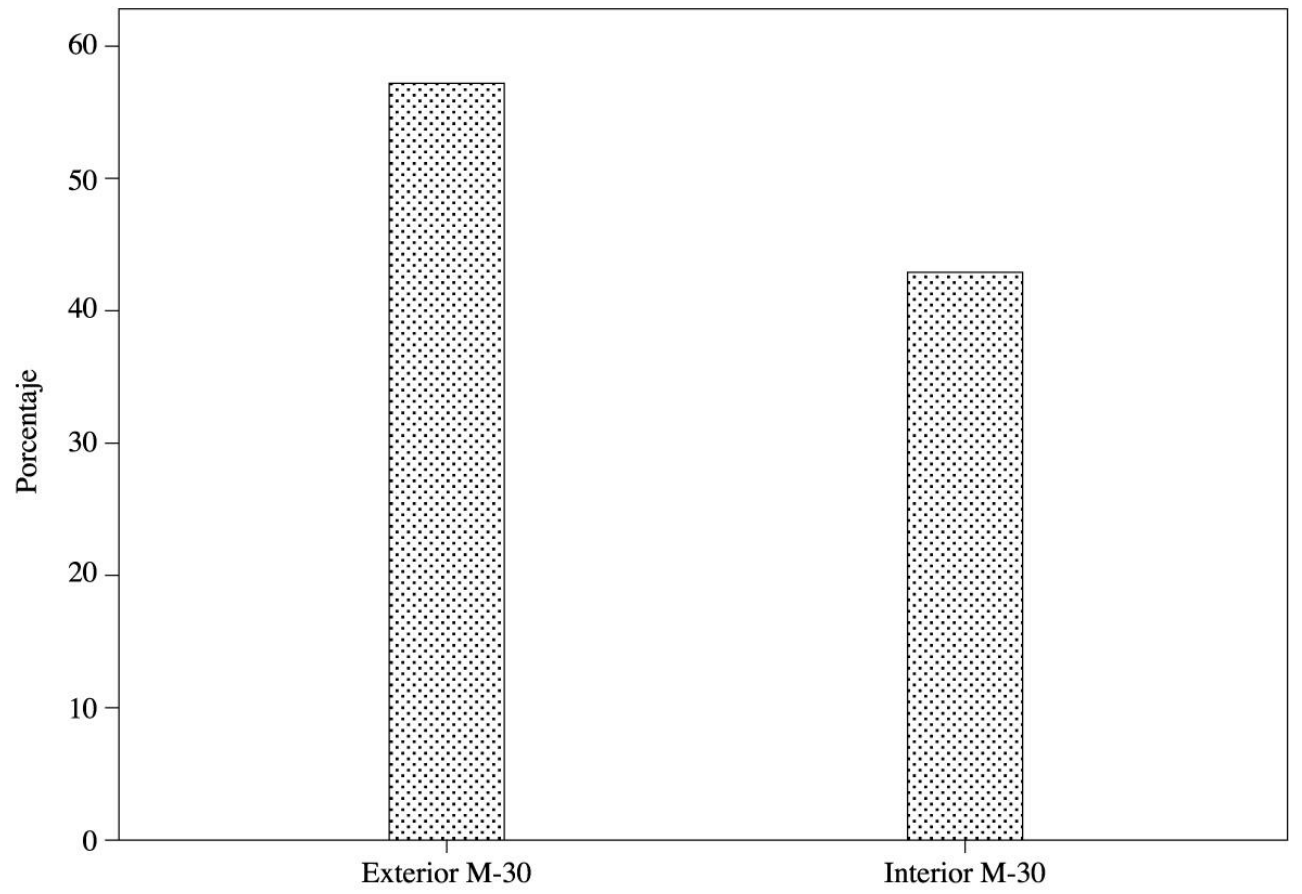

Fig. 5 Distribución por zonas de los locales en Madrid. 
Si en estas dos zonas analizamos los porcentajes de locales dedicados a las diferentes actividades, comenzamos a apreciar algunas diferencias: la cifra de locales dedicados a hostelería es cinco puntos mayor en la zona interior de la M-30 a la de los locales de la parte exterior, siendo la actividad en la que encontramos mayor diferencia. También es mayor el porcentaje de locales dedicados al comercio, pero sólo por un punto. Es significativo que el número de locales dedicado a servicios básicos para el residente, como la educación y la sanidad es mayor en la zona exterior (figura 6). Por lo tanto, una de las conclusiones que podemos extraer es que existe una especialización de los diferentes barrios de la ciudad, estando la zona central mejor preparada para las necesidades del visitante, mientras que la zona exterior tiene mejores servicios para el residente.

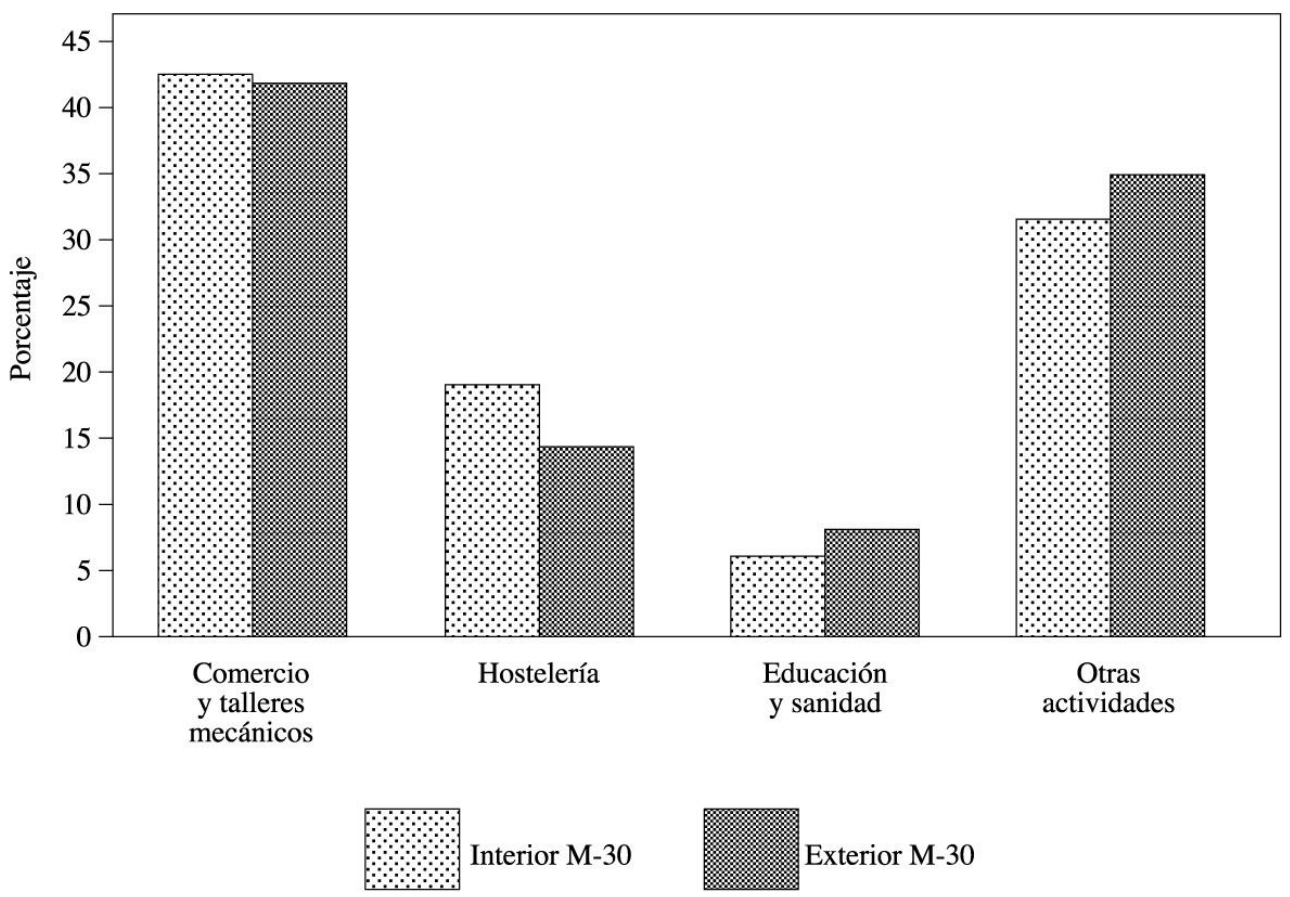

Fig. 6 Distribución por zonas de las actividades de los locales en Madrid. Fuente: Ayuntamiento de Madrid

Los datos disponibles que pueden ser analizados, desde febrero de 2015 hasta abril de 2017, son de un periodo de tiempo demasiado breve como para poder tener conclusiones claras, pero como hemos dicho, podemos observar algunas tendencias. Si vemos la cantidad de locales dedicados a las principales actividades a lo largo de este periodo, vemos como la única actividad que aumenta el porcentaje, aunque sea ligeramente, es la de locales dedicados precisamente al segmento de la hostelería. Tanto comercio, como sanidad y educación y el resto se estancan o reducen sus porcentajes (figura 7). 


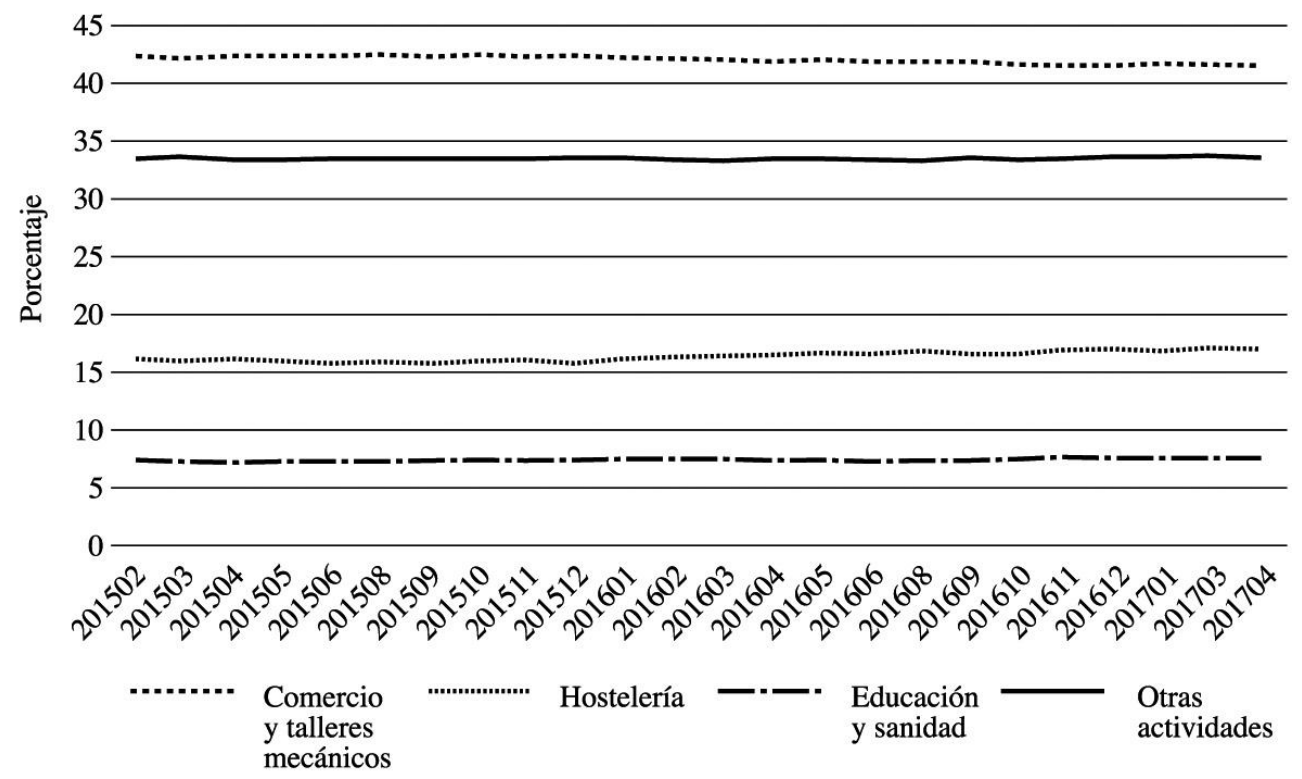

Fig.7 Evolución en función de las actividades de los locales en Madrid.

Fuente: Ayuntamiento de Madrid

\section{La ciudad corporativa}

La empresa de electrodomésticos AEG suele ser el ejemplo clásico cuando se habla de identidad corporativa. Los esfuerzos realizados por el tándem formado por Behrens y Neurath para dotar a la empresa alemana de una identidad propia, que consiguiese transmitir sus valores a través de su identidad gráfica, pero también de los productos que comercializaba, e incluso de sus edificios e instalaciones, no fueron en vano (Costa, 2004) Por ello hoy ocupan este lugar. Este trabajo es el que se entiende como la imagen que pretende proyectar una empresa: "la representación mental de un estereotipo de la organización, que los públicos se forman como consecuencia de la interpretación de la información sobre la organización" (Capriotti, 1992). Mucho se ha hablado en los últimos años de la importancia de crear una marca no solo para las empresas ya, sino también en torno a los países o ciudades. Un marca que genere una proyección de una cierta idea de ciudad, y que siga exactamente la lógica de la identidad corporativa que inaugurara la AEG para proyectar su imagen. La arquitectura es un elemento frecuentemente utilizado por las estructuras de poder a la hora de crear y transmitir una cierta imagen de la ciudad que representan. Pero más allá de la estructura física de los elementos, a la hora de generar esa nueva marca, hará falta acompañarla de una serie de experiencias que ayuden a construir dicha imagen. De la misma manera que para la AEG fue necesario unificar producto, comunicación y arquitectura bajo el paraguas de una marca reconocible para ofrecer la idea de electrodomésticos innovadores y fiables, la ciudad de Madrid utilizará su marca para promocionar su valor como ciudad de ocio, ligado a la cultura, la gastronomía o el shopping.

La intensificación de la competencia entre ciudades es señalada como una de las características de los proyectos neoliberales (Theodor et al., 2009), y los sectores de finanzas, cultura y turismo son, entre otros elementos, piezas clave a la hora de configurar una imagen urbana en la pugna con otras ciudades a la hora de atraer recursos económicos (Costa, 2004). En este caso, la promoción turística de la ciudad viene simbolizado por la marca ¡MADRID! que fue creada por la consultora Landor, y que en el caso de Madrid sirve como instrumento a la hora de posicionar la ciudad, dentro de la lógica neoliberal (Canosa y García, 2012). De este modo, la ciudad se plantea en si como una marca que debe conseguir transmitir unos ciertos valores, convirtiéndose en una ciudad corporativa, en la cual todos los elementos forman parte de una imagen total que unifique esfuerzos a 
la hora de proyectar Madrid como un gran centro de ocio para el turismo dentro de un proceso de brandificación (Muñoz, 2010) en el que pasa ser una marca en sí misma.

\section{Vistas de Madrid}

A la hora de plantear los escenarios para estas Vistas de Madrid, quisiera centrarme en algunas de las principales características que definen los espacios creados en la ciudad neoliberal y en los que podemos observar la tensión entre el centro y la periferia.

En primer lugar, podemos hablar de la "especialización absoluta en monocultivos como el turismo y el abanico de usos vinculados al entretenimiento urbano" (Muñoz, 2010). Es evidente el nuevo uso que dan en este sentido algunas de las grandes empresas a las antiguas sedes localizadas en el centro, como puede ser el caso del edificio Telefónica de la Gran Vía, reconvertido actualmente en tienda-exposición de sus productos, y también centro cultural ligado a la sede de la Fundación Telefónica. Un caso similar es el de la Fundación Mapfre en el edificio anexo de su antigua sede del Paseo Recoletos.

En la manzana que forman el triángulo de las calles Alcalá, Sevilla y la Carrera de San Jerónimo, justo al lado de la Puerta del Sol, y en pleno centro turístico de la ciudad encontramos un gran espacio reconvertido para el ocio. Los edificios, que entre otros albergaran las sedes del Banco Español de Crédito y del Central Hispano, han sido rehabilitados para dar lugar a espacios dedicados al shopping y a la restauración dentro del denominado Complejo Canalejas, incluyendo uno de los iconos que parece debe poseer toda gran ciudad, la tienda Apple. Por último, el Complejo AZCA (situado en la Castellana, entre el Estadio Santiago Bernabéu y los Nuevos Ministerios) que fue proyectado como el distrito financiero de Madrid, se revitaliza en base a las grandes superficies, y en la página web de turismo del ayuntamiento viene definido como "a mecca for shoppers". Tanto el antiguo edificio de Altadis en la calle Eloy Gonzo, como el de Telefónica en Rios Rosas o la agencia Efe en Espronceda cuentan en sus planes de renovación espacios dedicados a la restauración o a zonas comerciales que no existían en los proyectos originales.

Como segunda característica, podemos observar aquellas áreas en las que "la pérdida relativa o incluso absoluta de control sobre la ciudad por parte de las instancias de gobierno público” (Muñoz, 2010). Las ciudades corporativas en si son, como hemos visto, una emulación de la ciudad tradicional, pero bajo un control privado. Pero en este apartado cabría señalar especialmente aquellos lugares en los que la normativa es adaptada y modificada en aras de fuertes inversiones privadas, que supuestamente deben revertir a posteriori sobre el conjunto de la sociedad. El Edificio España puede ser leído como uno de los lugares donde ha existido tensión entre los intereses públicos y los privados. La salida del proyecto del grupo de inversión Dalian Wanda provocó diferentes reacciones entre los diferentes grupos representados en el Ayuntamiento, reavivando el debate de los que pensaban que la normativa era más importante que la inversión, y los que anteponían ésta como motor económico. También en esta línea ha sido criticado el Centro Canalejas por beneficiarse de los cambios de catalogación de alguno de los edificios que lo forman. En concreto, las modificaciones introducidas en la Ley de Patrimonio Histórico han sido y acusadas de haberse realizado para favorecer un tipo de actuaciones inmobiliarias que benefician a determinados intereses privados, pero suponen una pérdida de patrimonio para la ciudad. Tanto en Canalejas como en la tienda Apple, se crea una especie de escenografía, en el que sólo se mantienen las fachadas originales de los edificios, mientras que el interior es completamente adaptado a las nuevas necesidades.

La veduta, dentro del género del paisaje, se distingue por ser una representación de un territorio no ficticio. Esto no quiere decir que deba ser una visión fiel de la realidad, sino más bien, una visión particular como veremos. Creo que es importante hablar de tres atributos que considero relevantes para esta serie fotográfica. El primero es el de resaltar en la veduta el concepto de visión laica. Alain Roger (2007) defiende que en la pintura 
occidental, la invención del paisaje viene caracterizado por la unión de dos elementos: la laicización de la naturaleza, y el uso de una perspectiva que ayuda ordenarla, a componerla en diferentes planos. Este modo de desplazar hacia el fondo los elementos naturales, creando diferentes planos, le permite perder su carácter sacro. Es importante por lo tanto esta visión laica de los elementos representados en la configuración de la pintura de paisaje, de la cual es heredera posteriormente la veduta:

\begin{abstract}
Es más, ese orden de la escena, del espacio de la representación, sirvió no solo para hacer creíbles y verosímiles ciudades ideales o utópicas, sino que se proyectó sobre la imagen misma de la ciudad real, de Roma a Venecia, construyendo así el afortunadísimo género de la veduta, vistas de la ciudad y de sus arquitecturas a la vez pendientes de un afán progresivo de exactitud y precisión, en un proceso creciente de secularización del mundo y de la idea misma de ciudad que dejaba de ser figurada en sentido jerárquico, sagrado, ceremonial o monumental, para serlo en términos ciudadanos y laicos. (Rodríguez y Borobia, 2011).
\end{abstract}

Esta visión es la que se ha querido mantener en la serie fotográfica de Vistas de Madrid. Ciudadana y laica en el sentido de alejada de los elementos que configuran la visión oficial de la ciudad, de sus monumentos representativos, de su visión tópica, de su imagen corporativa. En las fotografías, las sedes de las empresas asumen ese papel de segundo plano, de fondo. En primer plano encontramos la naturaleza, las carreteras y autovías que cruzan por delante de ellas, mientras que los edificios quedan relegados al último plano. Esta voluntad por no mostrar las sedes de un modo institucional, en el que sean los elementos inequívocamente principales, es también una manera de mostrarlas desacralizadas, de eliminar su aura. Cuando Roger (2007) describe los paisajes de la Datar los define como "paisajes de-“ de decepción, de desecho... Al constatar la poca cantidad de paisajes naturales que fotografiaron los comisionados señala:

Le pregunté su opinión a Lucien Chabason, entonces jefe del gabinete del Ministro de Medio Ambiente. Me respondió 'Es el anti-cromo. Pero no hay lugar para sorprenderse cuando los artistas plantean algo tan fuerte. Es su papel. Están, como siempre, por delante de nosotros, anticipan nuestra experiencia'. Admito gustoso (...) que el arte ejerza esta función de anticipación (p. 122-123).

Estos anti-cromos de la Datar, como pueden ser también las postales alternativas de Francesco Jodice (1998), son laicas en el sentido de oposición al orden establecido, en oposición a la visión institucional o comercial de las zonas de nueva construcción en las ciudades. Por eso son anti, o alternativas, porque no representan lo esperado, y de ahí su importancia y capacidad de anticipación.

La segunda característica que debemos tener en cuenta es el lugar elegido a representar. En las primeras pinturas en las que el paisaje comienza a tener importancia, estos lugares son los paisajes moralizados (Busch 2001) en los que la naturaleza acompaña la escena bíblica, en lugares que no necesariamente identificados. Pero pronto comienzan a aparecer lo que consideramos propiamente pintura de paisaje, y entre esta, las escenas urbanas en la pintura holandesa, donde será habitual mostrar los diferentes usos de la ciudad. Por ejemplo, son habituales los paisajes invernales con patinadores, un retrato de los espacios del ocio (encontramos una analogía con las fotografías de Massimo Vitali o de Martin Parr retratando los momentos de ocio de la sociedad actual). Es el paisaje descriptivo holandés (Alpers, 1983) que alejado de la necesidad narrativa de la pintura italiana, supone una auténtica exploración del territorio. Heredero de este, nace lo que vamos a considerar propiamente las vistas de la ciudad, la veduta. Probablemente las venecianas sean las más recurrentes, y Canaletto uno de sus máximos exponentes a la hora de mostrar no solo la ciudad, sino también el ambiente y movimiento de la misma (Llorente, 2015). Detrás del auge del género se esconde una importante razón: 
A principios del siglo XVIII (...) el estado de Venecia declinaba. Con la mayor parte de su imperio perdido, la ciudad se convirtió en el escenario de la floreciente industria turística. Numerosos acaudalados visitantes extranjeros desembarcaron en la laguna veneciana para admirar las incomparables vistas y participar en la aparentemente interminable sucesión de carnavales, regatas, festivales y ceremonias públicas, ayudando a perpetuar los siete teatros, doscientos cafés y restaurantes, y los numerosos casinos y burdeles que ofrecía la ciudad. Eran los viajeros del Grand Tour del norte de Europa, y no los venecianos quienes comparaban las pinturas de vistas de Canaletto para recordar la majestuosa y etérea belleza de la ciudad. (Bumford y Finaldi, 1998)

El motivo pues por el que se pintaron estas vistas, o por qué el tema urbano tiene su momento de auge, está ligado de este modo al turismo en origen. La rica escuela italiana, y veneciana en particular, se nutre de la venta de sus cuadros a los participantes del Grand Tour, y en general a las clases pudientes del norte de Europa. Las regatas, la arquitectura de la ciudad, el Bucintoro... lugares y hechos para recordar de la ciudad. En las vistas que se presentan en la serie fotográfica de este capítulo, también encontramos edificios y localizaciones que pueden ser reconocidas por el ojo del visitante. Lugares que forman parte de un posible Grand Tour del siglo XXI, pero que, en vez de representar el imaginario para el turista, han sido modificados por él. Es la adaptación del paisaje urbano a las necesidades del nuevo viajero lo que da forma a estas vistas, y en ello radica su particularidad.

La elección del tema representado en la veduta, es también de gran importancia. El pintor escocés Thomas Jones viaja a Nápoles, y pinta una serie de vedute en las que llaman la atención los lugares seleccionados como motivo: una tapia, un balcón... vistas que reflejan el ambiente urbano, pero claramente alejadas de dónde sucede la acción de la ciudad o de la monumentalidad reconocible para el viajero. Esta elección del punto de vista, del lugar desde donde se mira y hacia donde se mira, es por lo tanto también parte de la ejecución personal que se hace de la veduta. El interés por Canaletto se incrementa al comprobarse que las vistas de Venecia no son fieles reflejos de la ciudad, sino interpretaciones (Corboz, 1974). Así es que, por último, en cuanto a características de las vedute, habría que hablar de la aportación que hace el autor del elemento representado, de la visión personal del lugar. 

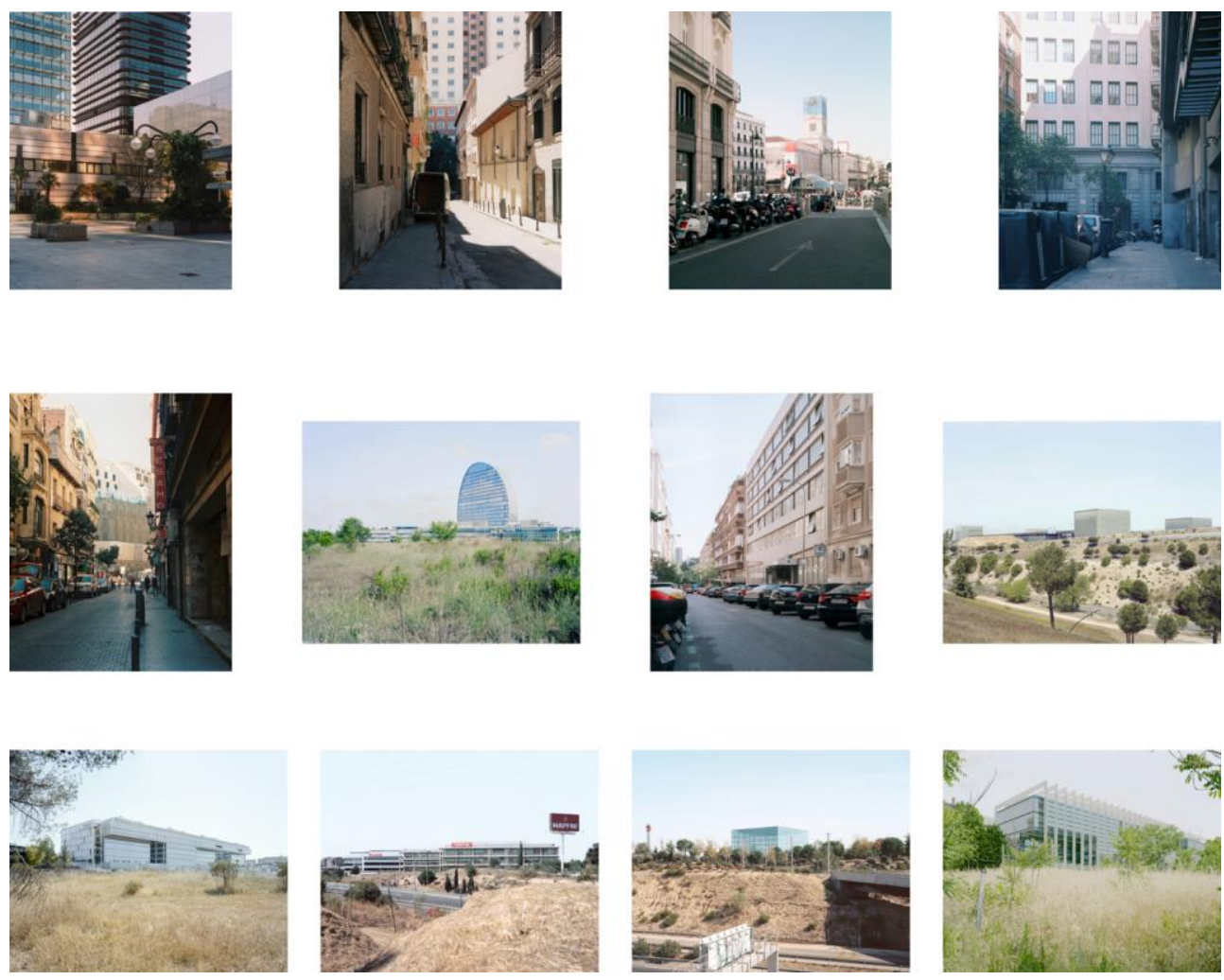

Fig.8 Vistas de Madrid. La ciudad corporativa. De izquierda a derecha y de arriba abajo: Azca; Edificio España, Tienda Apple en la plaza de Sol; Edificio Telefónica en la Gran Via; Complejo Canalejas; Ciudad BBVA; Antigua sede de la agencia EFE; Distrito Telefónica; Sede en construcción del Banco Popular; Oficinas Mapfre; Ciudad Financiera del Banco de Santander; Campus Repsol.

El libro que presenta la serie American nights de Paul Graham (2003), comienza con una serie de fotos sobrexpuestas, de zonas suburbiales degradadas. A pesar de que las fotos son prácticamente blancas al estar sobre expuestas, si esforzamos un poco la vista podemos observar claramente elementos identificativos: coches, descampados, paradas de autobús, y en el centro de la imagen siempre un transeúnte de color que vaga por el escenario. Intercaladas, encontramos otras, esta vez perfectamente expuestas, de los suburbios para blancos, con cielos de azul perfecto y asfalto impoluto, vacías de gente. Hacia final del libro comienzan a aparecer otras, que de manera opuesta, están subexpuestas, mostrando un oscuro downtown de ciudad americana. Las personas que vamos encontrando representan un segmento de la sociedad invisibilizado. Aunque las fotografías han sido mostradas en ocasiones de manera aislada, la visión de la serie completa y en el orden previsto aporta mucha información sobre el proyecto. Por lo tanto, es un valor que la fotografía puede aportar a la visión clásica de la veduta: el hecho de trabajar en series. Aunque las imágenes puedan funcionar de manera individual, es también importante el hecho de que se pueda hacer una lectura lineal de ellas.

En estas vistas de Madrid (figura 8) encontramos dos formatos de imágenes: verticales y horizontales. Las primeras se corresponden a la ciudad densa, que encontramos en la parte central de Madrid, y que muestran el nuevo modelo de ciudad que va surgiendo. Por oposición, encontramos las imágenes horizontales, donde el modelo urbano se hace disperso, y que están formadas por las ciudades corporativas de la periferia. La serie se presenta como un viaje que comienza en la zona centro, y en el que poco a poco van a intercalarse fotografías de zonas más alejadas, hasta que llegamos a un punto en el que solo se muestran las nuevas áreas de expansión. 


\section{La veduta anticipada}

Podemos por lo tanto concluir una serie de ideas a la vista de este proyecto:

Dentro de la expansión territorial de la ciudad de Madrid, las grandes empresas tienen un papel fundamental, no solo a la hora de ejercer poder como agentes de presión, sino también con la elección de la ubicación y formato de sus sedes. En los últimos años observamos como en Madrid las empresas más importantes tienden a desplazarse desde el centro hacia la periferia. El hecho de construir las nuevas ciudades corporativas en las afueras hace que la relación de éstas con la ciudad cambie con respecto a la que tenían las antiguas sedes del centro.

La competencia entre ciudades por la atracción del capital hace que los barrios céntricos se esfuercen en ofrecer un tipo de servicios no tanto pensados para los habitantes sino más bien para el visitante, fomentando un tipo de gestión de la ciudad en la que priman los intereses economicistas, lo que supone una nueva manera de configurar la ciudad.

La veduta es un género plenamente actual, que continúa ejerciendo su capacidad para analizar y narrar la vida y uso de las ciudades.

A diferencia de las vistas venecianas, en las que se trataba de mostrar aspectos de la ciudad en los que el visitante pudiese reconocer su experiencia, estas nuevas son las vistas anticipadas, en las que se muestra la transformación de la ciudad que intenta adecuarse a las necesidades y expectativas del potencial turista-cliente en aras de hacer una ciudad más competitiva a la hora de pugnar con otras por la atracción de visitantes.

\section{Referencias}

ALPERS, S. (1987). El arte de describir: El arte holandés en el siglo XVII. Madrid: Hermann Blume.

BANCO DE SANTANDER. Pensada para los empleados.

$<$ http://www.santander.com/csgs/Satellite/CFWCSancomQP01/es_ES/Corporativo/Acerca-del-Grupo/Sede-

corporativa/Pensada-para-los-empleados.html> Acceso 19 agosto 2017.

BOMFORD, D. y FINALDI, G. (1998). Venice through Canaletto's Eyes. Londres: National Gallery Publications Limited.

BORGDORFF, H. (2010) "El debate sobre la investigación en las artes". Cairon: revista de ciencias de la danza, n¹3, 2547.

BUSCH, W. (2001). "Landscape: the road to independence”.en Frings, J.. Landscapes from Brueghel to Kandinsky: The exhibition in honour of the collector Baron Hans Heinrich Thyssen-Bornemisza. (pp. 16-27). Ostfildern-Ruit: Hatje Cantz Publishers.

CANOSA ZAMORA, E. y GARCÍA CARBALLO, Á. (2012). "La construcción de la marca Madrid”, en Cuadernos Geográficos, 51, 195-221.

CAPRIOTTI, P (1992). La imagen de empresa: estrategia para una comunicación integrada. Barcelona: Consejo Superior de Relaciones Públicas de España.

CORBOZ, A. (1975). "Sur la prétendue objectivité de Canaletto", en Arte Veneta / Istituto Di Storia Dell'Arte, Università Di Padova. 205-218.

COSTA, J. (2004). La Imagen de marca: un fenómeno social. Barcelona : Paidós.

VOLUMEN. Entrevista a Alfonso Millanes. <http://volumen-mo.com/blog/2013/09/> Acceso 19 agosto 2017. 
GARCÍA ALGARRA, F.J. (2011). De Gran Vía al Distrito C. El patrimonio arquitectónico de Telefónica. [Tesis doctoral no publicada]. UNED, Madrid.

GRAHAM, P. (2005). Paul Graham: American night. Gottingen: Steidl MACK.

HACKWORTH, J. (2007). The neoliberal city: Governance, ideology, and development in American urbanism. Ithaca, N.Y: Cornell University Press.

HARVEY, D. (2009). Espacios del capital: hacia una geografia crítica. Madrid: Akal.

JODICE, F., y PETRAGLIA, S. (1998). Cartoline dagli altri spazi. Milano: Motta fotografia.

LOUKAITOU-SIDERIS, A., y BANERJEE, T. (1998). Urban design downtown: Poetics and politics of form. Berkeley: University of California Press.

LLORENTE, M. (2015). La ciudad: huellas en el espacio habitado. Barcelona: Acantilado.

MUÑOZ, F. (2010). Urbanalización paisajes comunes, lugares globales. Barcelona: Gustavo Gili.

PARDO ABAD C. J. (2004). Vaciado industrial y nuevo paisaje urbano en Madrid: Antiguas fábricas y renovación de la ciudad. Madrid: Ediciones La Librería.

RODRÍGUEZ, D. y BOROBIA, M. (2011). Arquitecturas pintadas: Del Renacimiento al siglo XVIII. Madrid: Museo Thyssen-Bornemisza.

ROGER, A (2007). Breve tratado del paisaje. Madrid: Biblioteca Nueva.

THEODORE, N., PECK, J. y BRENNER, N. (2009). “Urbanismo neoliberal: la ciudad y el imperio de los mercados”, en Temas Sociales, 66, 1-11. 